\title{
La dependencia de los medios de comunicación de masas en Chile*
}

\begin{abstract}
ArMand Mattelart, sociólogo y demógrafo belga, en Chile desde 1962 , en la actualidad es Jefe del Departamento de Desarrollo Social de ICrRa (Centro de Capacitación e Investigación en Reforma Agraria), Director de Investigaciones del Centro de Estudios de la Realidad Nacional (CEREN) y Profesor de la Escuela de Sociología de la Universidad Católica de Chile.

Es autor de varios libros sobre la realidad latinoamericana y chilena, entre ellos: Geopolitique du Controle des Naissances, París 1967 , Editions Universitaires; La Problématique du Peuplement Latinoamericain (en colaboración con Michele Mattelart), idem, 1964; coautor de Inlegración Nacional y Marginalidad, Editorial del Pacífico. Santiago de Chile, 1965; La mujer chilena en una nueva sociedad (en colaboración con Michele Mattelart), Editorial del Pacifico, Santiago de Chile, Ig68; La juventud, rebeldia $y$ conformismo, Editorial Universitaria, Santiago de Chile, 1970. Entre sus informes y artículos se destacan: Cuenca del rio Maule (Ministerio de Agricultura, 1965); La morfología social de una capital latinoamericana: Santiago de Chile, rg67 (Cuadernos de Economía $\left.N^{\circ}{ }^{11}\right)$; Estructura y Sistema de Estadisticas Educacionales (Ministerio de Educación, 1968); Prefiguración de la Ideología burguesa ( $\operatorname{CEREN} N^{\circ}$ ).
\end{abstract}

Se trata de ver cómo los modelos de conducta y las teorías correspondientes que transmite el medio de comunicación, liberal, reflejan una ideología dependiente, que no es sino un eslabón en la estrategia imperialista de la división internacional del trabajo. Debemos, en este campo específico, poner a prueba el slogan erigido por la clase dominante nacional acerca de la idiosincracia del capitalismo criollo. En la sección anterior, hemos podido demostrar que los detentadores de la libertad de prensa y de la libertad de opinión son los propietarios de los medios informativos, concluyendo en el hecho que la libertad de prensa es una libertad de propiedad. Si el medio de

* El presente artículo es un capítulo de la obra Los medios de comunicación de masas. La ideología de la prensa liberal de Chile, de Armand y Michele Mattelart y Mabel Piccini, publicada en Cuadernos de la Realidad Nacional del ceren, $\mathrm{N}^{\circ}$ 3, Marzo de 1970, dè la Universidad Católica de Chile, Casilla r r4-D. 
Armand Mattelart / La dependencia de los medios de comunicación de masas en Chile comunicación se halla además dependiente, estaremos obligados a admitir que, en la realidad, el principio absoluto de libertad de prensa permite a grupos monopolísticos nacionales constituirse, con plena libertad, en delegados de poder de un sistema de valores y aspiraciones extraños, insertado en un circuito de dominación.

Para contestar dicho interrogante dos àspectos esenciales merecen nuestra atención: por una parte, la dependencia material o la penetración de capitales, de publicaciones, de emisiones, de-películas, procedentes del extranjero en el medio de comunicación nacional; por otra parte, la dependencia ideológica o la coincidencia de los mensajes transmitidos por fuentes emisoras chilenas con modelos impuestos desde afuera. Este último punto, que nos' contentamos con esbozar, no encontrará su respuesta definitiva sino al término de las diversas lecturas ideológicas que se efectuarán en el curso de esta obra.

\section{LAA DEPENDENGIA MATERIAL}

Al recurrir a esta distinción arbitraria y puramente analítica entre dependencia material y dependencia ideológica, no pretendemos sustraer de su contenido ideológico la primera, sino que tratamos de precisar el tipo de enraizamiento de ambas formas de dependencia, susceptible de influir sobre el modo, según el cual, cada una impone modelos de conducta emanados de una cultura extraña. La dependencia material, se traduce, primero, en la implantación directa de un mensaje integramente importado de un fondo externo. Dicha operación se realiza a través de agentes nacionales chilenos que no son, entonces, sino los mandatarios de un mensaje gestado en otras sociedades. Es el caso por ejemplo de los comic strip, cuyos derechos de reproducción los ceden los trusts norteamericanos a editoriales chilenas. Cabe también otra modalidad, la que hace pasar el mensaje a través de una infraestructura creada para este efecto, en el territorio nacional por grupos extranjeros, y controlada directamente por ellos. Es el caso, por ejemplo, de ciertas agencias de publicidad instaladas en la capital, que no son más que empresas subsidiarias de grandes firmas norteamericanas.

El universo referencial de los mensajes transmitidos, en una situación de dependencia material, corre todos los riesgos de ser aquél de la fuente que lo emite, y su contenido ideológico reflejará esta reali- 


\section{EST T D I O S I N T ER N A C I O N A L E S}

dad. En cambio, en la dependencia que hemos llamado ideológica, la chilenización del mensaje está, en la mayoría de los casos, garantizada. Lo que no significa obligadamente que el mensaje no sea enajenado.

\section{Lapenetración del capital extranjero}

El medio de comunicación de masas chileno es indirectamente dependiente del capital extranjero, en la medida en que los grupos económicos nacionales que lo monopolizan están, ellos mismos, en colusión con el capital monopólico internacional en sus actividades bancarias, industriales, comerciales o agrícolas. En la sección anterior, hemos podido percatarnos del hecho que la penetración directa del capital extranjero en el medio de comunicación, se da en un grado mínimo y uno de los únicos casos notables sería aquel de la participación, a título de accionistas, de las compañías cupreras en la cadena radial Minería ${ }^{1}$. Por lo tanto, es principalmente desde el ángulo de la penetración indirecta, que se deben indagar los puntos de contacto de los monopolios chilenos con los trusts internacionales. En este caso la penetración norteamericana se demuestra claramente. Demos ejemplos: El presidente del grupo Mercurio-Lord Cochrane es también el presidente de la IBEC chilena (International Basic Economy Corporation $S$. A.) que administra el fondo de inversiones industriales y comerciales CRECINCO. Es merced a este fondo que numerosas empresas nacionales fueron nucleadas por inversiones norteamericanas procedentes, en su mayoría, del grupo Rockefeller.

En 1969 , la IBEC cubría un conjunto de sociedades relacionadas con los principales sectores de la actividad económica. Enumeremos algunos: Agropecuarias y ferias: Laguna Blanca, Tattersall y Tierra del Fuego (relacionadas las tres con el grupo Punta Arenas); Alimentos $y$ Bebidas: Compañías Cervecerías Unidas (grupo Edwards); Cemento y Construcción: Industria el Melón y Pizarreño

${ }^{1}$ Esta situación es bastante única. Cuando uno observa el caso del Brasil por ejemplo, la penetración directa de capitales extranjeros en el medio de comunicación de masas nacional es mucho más acentuada. Remitirse al estudio de Theotonio Dos Santos: El Nuevo Carácter de la Dependencia. Centro de Estudios Socioeconómicos (CESO), Universidad de Chile, Santiago, I 968 , pp. 65-74. 
Armand Mattelart / La dependencia de los medios de comunicación de masas en Chile (este último es controlado por el grupo Edwards y Matte Alessandri); Metalúrgicas: Electrometalúrgica creada por CORFo en asociación con la empresa privada, y Debentures CAP (en relación con el grupo Edwards, Banco Sudamericano, Kopper Co., First National City Bank, Anglo Lautaro); Neumáticos: iss (filial de General Tire \& Rubber Co.); Textiles: Yarur; Bancarias: Banco Sudamericano; Varios: Compañía Industrial (Edwards, Banco Español y Universidad Técnica F. Santa María); Pacífico Sur, Compañía Manufacturera de Papeles y Cartones (Matte-Alessandri). IBEC posee, además, capitales en las principales empresas de la industria de transformación, en vías de desnacionalización creciente $^{2}$; en MADECo (Manufactura de Cobre) que pertenece a la General Cable, de Estados Unidos, influido por el grupo financiero del Banco de Chile y Edwards; en mademsa (Manufacturas de Metales S. A.) que está en estrecha relación con el grupo económico controlado por el Banco Sudamericano y Matte Alessandri y en compac (Compañia de Productos de Acero); en su directorio figuran propietarios del diario La Tercera y personeros del grupo Matte Alessandri y sus accionistas principales son Butler Manufacturing Co. (Consorcio norteamericano), Fides Union Fiduciaria (Consorcio Francés), Fisk Import S. A. (consorcio norteamericano). compac es un caso típico de sociedad financiada por la empresa de inversiones multinacional Adela. ${ }^{3}$.

Se dan estos ejemplos, únicamente, para ilustrar la penetración del capital extranjero en la actividad económica nacional, penetración tan profunda que resulta difícil disociar los intereses mutuos.

En materia de medios de comunicación de masas, la solidaridad en-

${ }^{2}$ A dichas sociedades habria que agregar las empresas del mismo sector de actividad que están ligadas a los EE.UU., por otros canales: American Screw S. A. controlado por la Textron Industrie Inc. (Consorcio norteamericano) y por el grupo Bco. Chile y Bco. Edwards; Cobre Cerrillos, controlado por el grupo Bco. Panamericano y Bco. del Trabajo.

Sobre la desnacionalización - nueva política del imperialismo- de la Economía chilena, véase Mario Vera "Detrás del cobre" en Cuadernos de la Realidad Nacional, Santiago, $\mathrm{N}^{\circ}$ 2, enero de 1970 .

${ }^{3}$ La lista de las sociedades donde están invertidos fondos de la IBEC, se extrajo de la revista Causa Marxista Leninista, Santiago, $\mathrm{N}^{\circ}$ 9; junio de 1969; pág. 35 . Ha sido completada con datos recogidos en las Actas del Senado del 20 de agosto de $196 \mathrm{~g}$, op. cit. reproducidas en $E l$ Mercurio, 23 de agosto de 1969 , pág. 17 . 
E S T U D.I.O:S I N T E.R.NA C I O N A L E S

tre grupos monopolísticos nacionales e internacionales se ha cristalizado en las organizaciones que, constituyéndose en una verdadera red de proteçción de ințereses, se han convertido en grupos de presión moral. Es así como la Sociedad Interamericana de Prensa (sIP) fundada en Nueva York en 1950 , reagrupa los. grandes diarios pertenecientes a los consorcios norteamericanos y latinoamericanos. No por casualidad presidía esta sociedad en 1969 , el presidente del grupo Edwards. Promoviéndose en defensora de los grandes principios de la libertad de opinión, la activa Comisión de la libertad de prensa impugna la censura de los generales brasileños a la vez que là nacionalización de algunos medios informativos por los generales peruanos, siendo la única. dimensión común a ambos procesos un alcance al monopolio de la libertad de la propiedad de la prensa.

\section{La colonización del dominio:áplicicitario}

El medio de comunicación es directamente dependiente del capital extranjero en la medida en que: 1) el medio se encuentra bajo el control directo del extranjero (control de acciones o control del capital inicial); 2) el medio depende para subsistir de un financiamiento procedente de empresas foráneas,

Es en el dominio de la publicidad que la penetración externa directa se hace sentir de manera más aguda, y esto bajo los dos puntos de vista mencionados: 1) instalación de subsidiarias de firmas norteamericanas, relacionadas ellas mismas con la red del gran capital internacional; 2) presión de la empresa extranjèra sobre el medio de comunicación de masas, a través de la demanda publicitaria. Determinar esta penetración es tanto más importante en cuanto la publicidad puede considerarse como plaça giratoria para la creación de necesidades y para la transmisión de pautas de comportamientos y de aspiraciones de consumo de otra sociedad.

\section{Las filiales de unia red norteamericana}

Entre las veinte agencias publicitarias que existen en el pais se encuentran 5 agencias, filiales chilenas de firmas norteamericanas, 2. de las cuales son las más importantes. En Ig68, la Mac Cann Erickson chile- 
Armand Mattelart / La dependencia de los medios de comunicación de masas en Chile

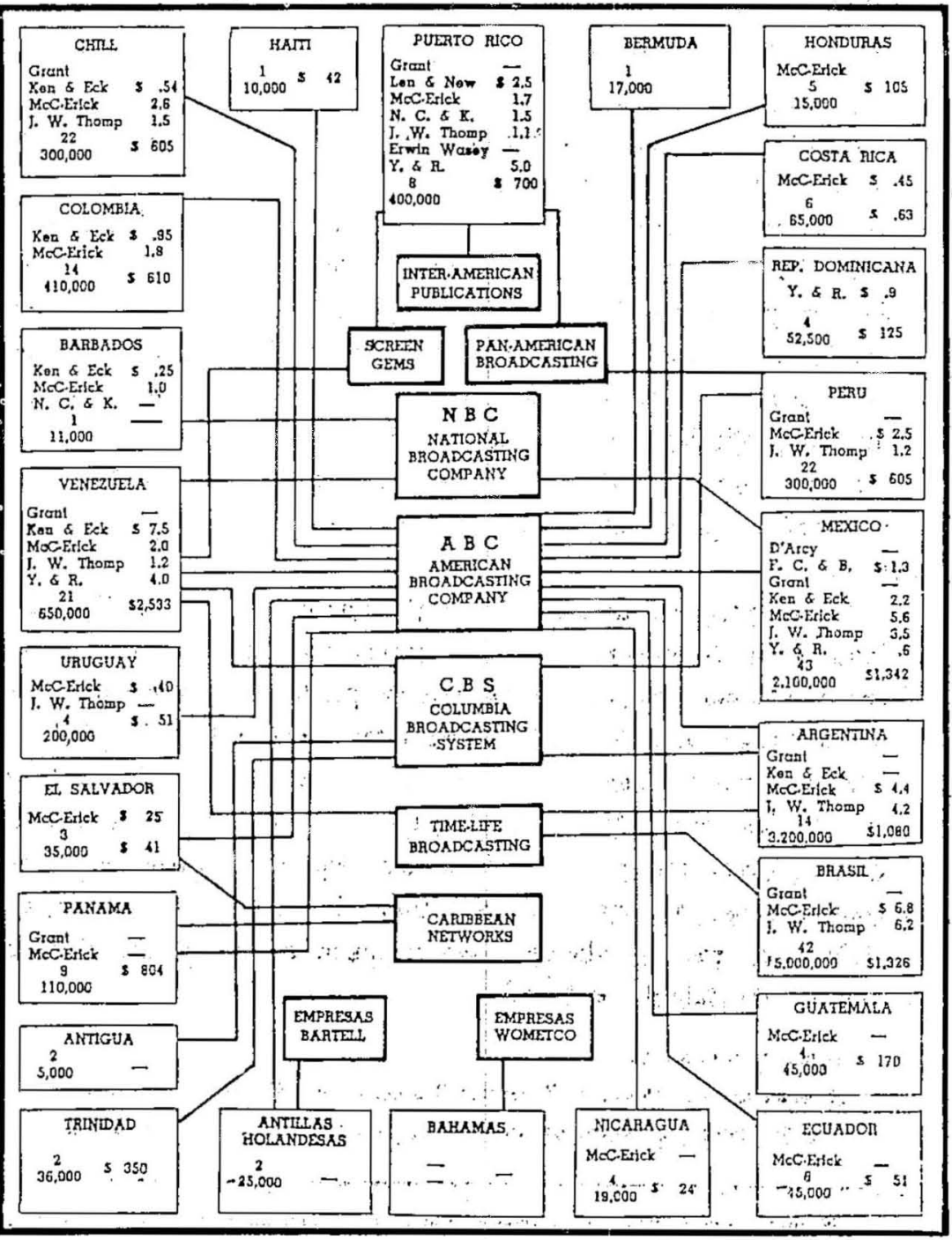

Fuente: Panorama Económico Latinoamericano. La Habana, año $9,1969, \mathbb{1}^{\circ}, 3^{12}, \mathrm{p} .6$. El gráfico muestra los países en los que las grandes empresas de Estados Unidos de Televisión (más agencias de anuncios, etc.) tienen inversiones, según el Television Faclbook $1967 \mathrm{y}$ el Television Magazine de octubre 1966. Debajo del nombre del pais figuran las agencias y el total de anuncios que facturan (en millones de us\$). Las dos cifras a la izquierdá indican el número de estaciones de T.v. y el número de aparatos de T.v. en cada páis. Las cifras en la esquina derecha inferior anuncian el monto total de las inversiones directas de Estados Unidos en cada pais, en millones de dólares.

Abreviaturas: F. C. \& B.: Foote, Cone \& Belding; Kent \& Eck: Kenyon \& Eckhardt; Len \& New: Lennen Newell; Mc C-Erick. Mc Can Erickson; N. C. \& K.: Norman, Craig,

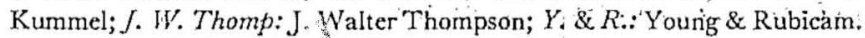


E S T U D I O S I N T E R N A G I O N A L E S

na, efectuaba la publicidad de $5 \mathrm{I}$ firmas comerciales entre las cuales 18 eran firmas extranjeras ${ }^{4}$ y facturaba, en 1967 , un total de anuncios que alcanzaba 2,6 millones de dólares únicamente para Chile (a título de comparación, en Brasil estas cifras subian a 6,8 millones de dólares). La $J$. Walter Thompson Chilena realizaba la publicidad de $5^{6}$ firmas, entre las cuales 27 pertenecían a firmas extranjeras, y facturaba en 1967 un total de anuncios de 1,5 millones de dólares. La Kenyon y Eckardt chilena, menos importante, lo hacía para 22 empresas (5 extranjeras). La Grant Adversiting, última agencia de este grupo relacionado con el American Broadcasting Company ( $\mathrm{ABC}$ ), reunía la publicidad de 30 firmas (7 extranjeras). A estas agencias habria que sumar la Storaindt (alemana) y la West Coast Publicity concentrándose ésta, exclusivamente, en productos y servicios extranjeros.

Cabe destacar, cuanto antes, que el número de firmas es sólo uno de los indicadores del volumen de sus negocios y a menudo no es el más decisivo. Cuando se examina el tipo de productos o servicios y la lista de las firmas para las cuales hacen estas agencias la publicidad, se percibe que son las agencias subsidiarias las que monopolizan, la mayoría de las veces, la actividad publicitaria de los sectores estratégicos de la economía y sobre todo de las filiales de los trusts también norteamericanos. Comparemos a título ilustrativo dos agencias, una chilena y una dependiente, cuyo volumen de firmas atendidas es del mismo orden (alrededor de 50$)^{6}$.

PUBLICIDAD CONDOR:

Asociaciones de Ahorro y Préstamo: 8 asociaciones, Campaña del Ahorro, Caja Central de Ahorros y Préstamos; Bancos y seguros: Banco Central, Banco de Chile, Ban-

${ }^{4}$ El número de firmas que en 1968 confiaban su publicidad a estas agencias se extrajo del Boletin del Achap: Lista de Clientes de Agencias asociadas al 30 de julio de 1968.

${ }^{5} \mathrm{El}$ total de anuncios que facturan (en millones de dólares) se extrae de Panorama Económico Latinoamericano, año $\mathrm{N}^{\circ} 9, \mathrm{~N}^{\circ} 3^{12}$, La Habana, 1969 , (según dicha fuente los datos provienen de las publicaciones Television Fact Book, 1967 y Televisión Magazine de octubre de 1966).

${ }^{6}$ Esta larga lista de nombres de firmas extranjeras es un ejemplo más de la penetración del capital norteamericano en la economía chilena $y$, por el mismo hecho, viene a completar el panorama de la dependencia esbozado en los primeros acápites. Las listas se extraen de la fuente ya citada Lista de clientes (ACHAP), julio de 1968 . 
Armand Mattelart / La dependencia de los medios de comunicación de masas en Chile co del Estado de Chile, Cooprev (Seguros); Hoteles: Asoc. de Hoteles, Restaurantes y similares, 5 hoteles, Termas de Panimávida; Riquezas básicas: Sociedad Minera el Teniente S. A.; Plantas elaboradoras melal: Mademsa S. A., Madeco S. A.; Instituciones fiscales $y$ colectividades politicas: Direccion de Turismo, Instituto de Fomento Pesquero, Instituto de Capacitación Profesional, Junta de Adelanto de Arica, LAN Chile, Municipalidad de Santiago, Corporación de Servicios Habitacionales, Partido Demócrata Cristiano; Industrias químicas: Cámara de la Industria Farmacéutica, Dow Quimica Chilena, S. A., Laboratorio Chile (Sección Agrícola), Lápices Brc, Petro Dow S. A., Petroquimica S. A.; Clubes deportivos: Club Deportivo Universidad Católica, Club Deportivo Magallanes; Propiedades: Constructora Fortaleza, Edificio La Alcaldesa, G. Pérez F., Münchmeyer; Automóviles: Difa (Venta); Maquinarias: Agencias Graham S. A., S. A. C. Saavedra Benard; Máquinas Coser: Vigorelli; Neumáticos: Firestone; Varios: Cristavid S. A., Té Club, Antivero (artefactos hogar). Alusa foil (papel aluminio), A. Mallea, Calzados Mingo, Luxo Tex (textiles), Centro de Estudios Aplicados (CEA). Medios de comunicación: Radio Balmaceda.

\section{J. WALTER THOMPSON:}

Riquezas básicas: Anaconda, Compañia de Petróleos de Chile (COPEC), Corporación de Ventas de salitre y yodo de Chile, Mobiloil de Chile Ltda.; Bancos: First National City Bank; Automóviles y repuestos: Ford Motor Company, Daly, Jones y Cia., Champion Spark Plug, Industria Lee, Filter de Chile, Nieto Acisa, Sodial (Concesionario Ford); Soinbal (balatas); Aviones Mc Donnell Douglas International Neumáticos: Goodyear Tire and Rubber Co.; Artículos eléctricos: Philips Chilena S. A., Sanger Sewing Machine Co., Soclima (aire acondicionado...), Famasol; Productos quimicos y farmacéuticos: Davis Laboratorios, Cirsa de Chile S. A. (Sloan), Laboratorios Mayer S. A., Laboratorio Squibb, Indus Lever SAaI, Quimicas Unidas S. A., S. C. Johnson and Son (Ceras...), Squirrel y Cia.; W. F. Young; Bebidas: Pepsi Cola International, Compañia Cervecerias Unidas; Alimentos: Ambrosoli, Alimento Purina, Compañía de Chicles Adams, Compañía Industrial, Chiprodal (Nestle, etc.), Fábrica de Pan Ideal, Frigorifico San Miguel, General Mills de Chile S. A., Molinos y Fideos Carozzi, Savory S. A., Weir Scott; Calzados: Bata S. A. C. y Catecu; Artículos Fotográficos: A. Reifschneider, Kodak Chilena Ltda., Máquinas Oficina: Olympia (Chile) Ltda., Grace y Cía. (Chile) S. A.; Textiles: Fábrica de Paños Continental, Miguel Labán Hnos. y Cía,, Industrias Textiles Pollak Hnos. y Cía. S. A.; Materiales Construcción: Fanaloza; Varios: Marmicoc, Industrias Montero (Muebles desarmables), Gobierno de Australia, Pan American World Airways Inc., Rolex (relojes); Medio de comunicación: Selecciones del Reader's Digest.

\section{La demanda publicitaria}

$\mathrm{Si}$ es relativamente fácil establecer que la publicidad es la fuente principal de recaudación de la prensa, la radio y la televisión, en cambio es 
ESTUDIOS INTERNACIONALES

mucho más difícil cuantificar la presión que ejerce la empresa extranjera, a través de su demanda publicitaria. Algunos indices que se sumar a aquellos que hemos mencionado en los acápites anteriores permiten orientarnos en el sentido de un diagnósticọ más completo.

$-45 \%$ de los avisos pagados en el canal de T.V. 13 pertenecen a firmas extranjeras ${ }^{\top}$.

-La gran mayoría de los informativos radiales están patrocinados por firmas extranjeras. Demos ejemplos:

Informativo Anaconda (Cooper Mining) (Radio Minería de la Serena, Antofagasta, Viña del Mar, Santiago, Radio Sago, Osorno; Radio Almirante Latorre, Talcahuano).

Informativo Reporter Esso (Standard Oil) (Radio Mineria Antofagasta, Viña del Mar, La Serena, Santiago, Talca, Radio Atacama, Copiapó; La Discusión de Chillán; Radio Imperial, Temuco; La Cruz del Sur, Punta Arenas).

Informativo El Teniente (Radio Magallanes, Santiago).

Informativo Life (Radio Agricultura, Santiago).

Habría que agregar el teletipo INSA (General Tire \& Rubber Co.), los programas auspiciados por la RCA Victor, etc.

Filtrado de información por las agencias noticiosas

El proceso de transmisión de las noticias atinentes a la situación internacional es, sin lugar a duda, uno de los puntos más críticos de la dependencia del medio de comunicación de masas nacional. El empleo de corresponsales particulares, pertenecientes a un diario o a una radio, no es sino esporádico, llegando la mayoría de las informaciones encauzadas por agencias Noticiosas extranjeras. Ahora bien, en este dominio, sobre el monopolio extranjero viene a superponerse el monopolio de un grupo nacional. Veamos sus mecanismos:

1. Las noticias $y$, a veces, los comentarios relativos a la situación internacional llegan a través de numerosas agencias noticiosas entre las cuales se encuentran: La upi, (United Press International) la

${ }^{7}$ Datos obtenidos directamente de la Dirección del Canal de TV. 13. 
Armand Mattelart / La dependencia de los medios de comunicación de masas en Chile Ap (Associated Press), el New York Times, las tres con sede en Nueva York; la Afp (Agence France Presse) de Paris, lä agencia inglesa Reuter, instalada en Buenos Aires; la agencia ANSA (Agencia Nacional de Prensa Italiana) con sede en Roma; la agencia Prensa Latina, procedente de La Habana y la Agencia Tass, procedente de Moscú.

2. Todas las agencias noticiosas establecidas en países del área capitalista están en manos de grupos, cuyos intereses económicos' están bien delimitados.

- Los propietarios de la upi son los grupos petroleros de Texas (por tal motivo hubo gran énfasis sobre noticias del petróleo peruano).

- La agencia AP., es una cooperativa de socios y capitales privados. Son socios de la cooperativa todos los grandes diarios de América Latina de orientación conservadora.

-La agencia France Presse tiene como dueños, capitalistas privados franceses. Sólo recientemente esta agencia renunció a la subvención estatal por motivos de mayor autonomía.

- La agencia Reuter está cor.trolada por capitales privados ingleses.

3. La mayoría de estas agencias cubren de manera predominante algunos tipos de información. Es asi como la AP y la UPI se centran principalmente en las noticias relativas a la rivalidad Washington-Moscú, enfatizando las noticias referentes a la guerra de Vietnam y a los paises del área socialista y dándole, de hecho, poca importancia a América Latina. No obstante, suele admitirse que la upi cubre mejor al subcontinente y tiene también la reputación de ser más liberal y más abierta, razón por la cual es la agencia noticiosa de mayor cauce informativo. La agencia Reuter se interesa más especialmente en las noticias de Africa y Asia, mientras que la agencia France Presse es aquella que hace más hincapié en los sucesos latinoamericanos. En cuanto al New York Times, que llega a Chile por medio de la West Coast, se ha especializado en el clespacho de reportajes (a 7 u 8 diarios).

4. El grupo El Mercurio, posee la exclusividad de las grandes agencias del área capitalista: AP, Reuter, France Presse y New York Times ${ }^{8}$. Los

${ }^{8}$ Sólo la up es utilizada por todos los diarios chilenos. Sin embargo cabe recalcar que los teletipos de esta agencia también están instalados en el edificio de El Mercurio, a pesar de que esta agencia tiene sus propias oficinas para entregar estas noticias a todos los diarios $y$ radios del país. 
E S T U D I O S I N T E R N A C I O N A L E S

teletipos de estas agencias funcionan en el edificio de ese diario. Antes de llegar al público nacional las informaciones provenientes de estas agencias pasan por un doble proceso de decantación, en Estados Unidos o en Europa y en Santiago. Sobre r 20 mil palabras diarias que recibe el diario a través del teletipo, sólo nueve mil llegan al público.

Todas las noticias importantes -en general las de orden político- que vienen del exterior pasan por la dirección del diario y por tanto no son seleccionadas por los periodistas de la sección ${ }^{9}$.

\section{Televisión, cine e industria disquera}

No es un secreto para nadie que, en todos los paises latinoamericanos, los programas de T.V. de origen nacional son escasos ${ }^{10}$. Este alcance vale tanto para los canales de T.v. controlados por grupos económicos como para aquellos que dependen de instituciones públicas y culturales. En Chile, como la mayoría de los canales; entre ellos los dos más importantes, son controlados por las universidades, esta situación tiende a evolucionar paralelamente al progreso de la Reforma Univer-

${ }^{9}$ Sobre las implicaciones nefastas de esta selección por la dirección, desde el punto de vista de la libertad de prensa y de opinión $y$ de la independencia del periodista $y$ de su dignidad frente a los propietarios de la prensa, consúltese Jean Schwoebel: La Presse, le Pouvoir et l'Argent, Editions du Seuil, París 1968. (EI autor relata en este libro la experiencia de Le Monde sobre las "Sociedades de Redactores" donde el diario está controlado por los mismos periodistas, una de las únicas maneras de hacer del trabajo periodístico una suerte de servicio público de la información, en las condiciones necesarias de independencia $y$ de competencia. Citemos a este autor: "Cabe advertir que la libertad de prensa que tan a menudo invocan tantos directores de diarios en coloquios, congresos y banquetes en los cuales participan se resume en realidad en la libertad de conducir sus negocios a su manera. De ninguna manera significa para ellos lo que debería ser: la independencia rigurosa de sus colaboradores $y$ el robustecimiento constante del pluralismo de las ideas y de las opiniones", p. 2 I.

${ }^{10}$ Según informaciones recientes: "En Lima, dos tercios de la programación son peliculas norteamericanas, argentinas y mexicanas. En Costa Rica, los programas extranjeros oscilan entre un 80 y un $90 \%$. En el Ecuador, son foráneos el $73 \%$. En Brasil, una cuarta parte, un porcentaje similar al argentino" citado en "El vacio cultural de la Television", Visión, Santiago de Chile, Vol. $37 . N^{\circ} 8$, 10 oct. de 1969 . Según esta misma fuente, América Latina consume anualmente seriales y películas nofteamericanas por no menos de 80 millones de dólares. 
Armand Matlelart / La dependencia de los medios de comunicación de masas en Chile sitaria $^{11}$. Pero, a pesar de ello, la dependencia frente a seriales y películas importados de EE.UU. permanece aún en un grado elevado.

Hemos podido reconstituir para el año $1968^{12}$ un marco relativamente completo de la importancia de los programas de origen extranjero en uno de los canales de televisión más importantes (canal 13):

a) Porcentaje de tipos de programas atendiendo a los minutos de transmisión (semanal).

Porcentaje programas nacionales:

(2.1 70 minutos) $54 \%$

Porcentaje programas extranjeros:

$\frac{(1.810 \text { minutos }) \quad 46 \%}{(3.980 \text { minutos }) 100 \%}$

b) Tipos de programas extranjeros (en base a los minutos) $=46 \%$

Porcentaje películas $96 \%$

Porcentaje programas musicales

Porcentaje programas culturales

$0 \%$

c) Costo de arrendamiento de programas extranjeros ${ }^{13}$.

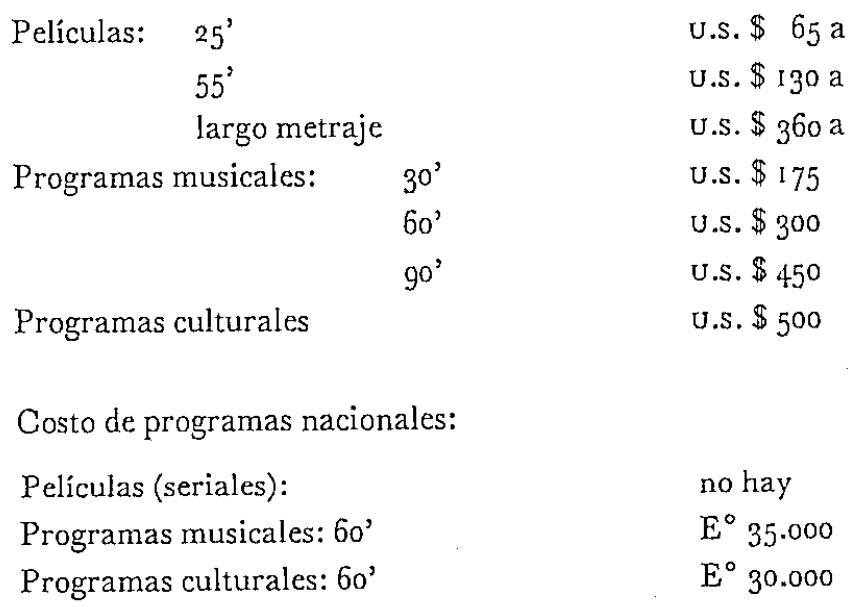

${ }^{11}$ Véase por ej. los programas del tipo Memorándum para Chile que implantó el canal i 3 en el curso del año 1969 , (entre otros temas se tocaron la situación de la mujer, de la juventud, la - marginalidad, la reforma agraria, etc.).

${ }^{12}$ Datos obtenidos directamente de la dirección del canal aludido.

${ }^{13}$ Existe un régimen especial de importación de los programas extranjeros: se utiliza la internación temporal por ser arrendados, no afecto a impuestos por estar exentos. 
Por último un dato revelador: los programas de mayor sintonía:

Nacional: Telenoche: $92,3 \%$ sobre T.x. encendidas, siendo el porcentaje de T.v. encendidas de $70,3 \%$ del total. de televisores. Recordamos que en 1969 , el número de aparatos en Chile fluctuaba entre 250.000 y 300.000 .

Extranjero: Bonanza: $94 \%$ sobre T.v. encendidas ( $T . v$. encendidas, 75,5 por ciento).

La mayoría de las películas y seriales norteamericanas para la televisión, son distribuidos en América Lațina por el American Broadcasting Company ( $\mathrm{ABC}$ ), en relación íntima con la cadena de agencias de publicidad (MIc Cann Erickson, Grant, J. Walter Thompson, véase el cuadro adjunto): Los dos otros trusts norteamericanos que controlan el universo televisivo en América Latina, lo constituyen el National Broadcasting Company (NBC) y la Columbia Broadcasting System (CBS).

La dependencia se acentúa aún más en el dominio cinematográfico. En los cuatro últimos años, puede estimarse que la producción nacional no ha superado un promedio de dos películas al año. Por tanto, la casi totalidad de las películas proyectadas en Chile proceden del extranjero.

Según datos recogidos directamente del Banco Central ${ }^{14}$ el valor de la importación de películas foráneas alcanzó en 1968, a u.s.\$633.946. En dicha suma, las películas de proveniencia norteamericana participaban por U.s.\$ 359.063. El segundo país proveedor resultaba ser México (U.s. $\$ 98.537$ ); el tercero, Italia (83.292); el cuarto, Argentina (31.8I I); el quinto, Inglaterra (27.057); el sexto Francia con $15.7^{6} 7$ dólares.

En materia de noticiarios, programas educativos y cientificos, la suma total era mucho menor: un total de i 9.257 dólares, en el cual Estados Unidos participaba en $9.43 \mathrm{I}$ dólares y México en 5.131 dólares. Huelga decir que todas las grandes firmas cinematográficas norteamericanas tienen una sede en la capital (Columbia Pictures of Chile, Inc.; Metro Goldwyn Mayer; Paramount Films; Twentieth Century Fox; Wárner Bross; Seven Arts (South) Inc., etc. ${ }^{\mathbf{1 5}}$.

\footnotetext{
"Banco Central, Anuario de importaciones, 1968, establecido a partir de datos de la Superintendencia de Aduanas.

${ }^{15}$ Cabe recalcar el aspecto diferencial de la exposición a los diversos tipos de películas, según el estrato social. Véase A. y M. Mattelart: Juventud chilena: Rebeldia y Conformismo,
} 
Armand Mattelart. / La dependencia de los medios de comunicación de masas en Chile

A diferencia de lo que ocurre en la mayoría de los países latinoamericanos, là industria disquera instalada en el país provee la totalidad del mercado chileno de discos. La importación de discos está prohibida. Los discos de artistas extranjeros son, por lo tanto, editados en Ghile pagándose los derechos : correspondientes. Las dos únicas empresas que elaboran discos son, por una parte, la RCA Victor, subsidiaria chilena de la RCA International Ltd. Canadá asociada en forma mixta con la Corporación: de Fomento: (CORFo), organismo estatal; . por otra, la ODEON, de capitales principalmente inglesas (Columbia Gramophone Company Limited, Em Overseas Holding ,Limited). Las otras editoras disqueras deben, por lo tanto, recurrir a. una de las dos empresas para grabar sus propios discos.

Otros datos interesantes ${ }^{16}$ : en 1966 , existía un total de medio millón de tocadiscos y la producción de long playing alcanzaba 800.000 unidades; aquella de microsillon; 1.200 .000 unidades. Lo que hacía que Chile, en América Latina, representara la proporción más alta de venta de dis$\cos$ (en relación con el número de habitantes). Por lo demás, là industria disquera está intimamente secundada por los Fan Magazines, tales como Ritmo, Ecran, Nuestro Mundo, Topsi.

En la producción disquera, la llamada música popular lleva ampliamente la delantera con un $70 \%$ de los discos, la siguen en el orden el folklore $(20 \%)$ y la música selecta (10\%). Difícil es establecer la proporción de discos extranjeros en la producción nacional, pero según datos oficiosos, oscila alrededor del 65 a $75^{17}$.

Editorial Universitaria, Santıago, en prensa. Pudımos comprobar que alrededor del $20 \%$ de las tres últimas peliculas vistas por los jóvenes universitarios, en los seis meses anteriores a la encuesta, pertenecen a la categoria del nuevo cine europeo (Bergman, Godard, Lelouch...) que se caracteriza por la búsqueda estética, metafísica o que pone en tela de juicio el orden social. Esta proporción disminuía al $3 \%$ en los jóvenes obreros. Las otras peliculas pertenecian al repertorio clásico de peliculas norteamericanas.

${ }^{16}$ Datos obtenidos a través del Disjockey Ricardo Garcia que los publicó en Bill Board1967. 1968. International Buyer's Guide of the music record industry, Nueva York, August 19, 1967 , Sección 2, pág. 219.

${ }^{17}$ Anotemos que según la encuesta ya citada que realizamos en diversos sectores juveniles, los jóvenes obreros y campesinos tienen clara preferencia por los cantantes chilenos y latinoamericanos en general. A título de ejemplo, digamos que para $59 \%$ de jóvenes obreros que prefieren a cantantes chilenos, sólo se encuentran $8 \%$ de universitarios en la misma situación. 
Como en todos los países del mundo, los quioscos chilenos están provistos de numerosas revistas importadas. (Life, Times, The Economist, etc.) Pero su distribución dista muchos de ser masiva. El mercado de las revistas dependientes es alimentado por revistas de origen principalmente norteamericano, cuyos derechos compran editoriales. chilenas que las editan y distribuyen o por otras, también del Norte, comercializadas por empresas subsidiarias de un trust periodístico foráneo. Aislamos un primer grupo bastante heterogéneo.

-Vanidades Continental, revista femenina bimensual, cuya sede se encuentra en Miami, publicada y distribuida por el grupo Lord Cochrane (40 mil ejemplares).

- Selecciones del Reader's Digest, cuyo tiraje alcanza a 120 mil ejemplares mensuales se imprime en la Editorial Lord Cochrane y está distribuida por la Filial chilena de la Reader's Digest ${ }^{18}$.

-Corín Tellado, revista seudoamorosa, de origen español, publicada semanalmente por el grupo Lord Cochrane, a razón de 35 mil ejemplares.

-Visión, revista de información general que saca 30 mil ejemplares semanalmente. Impresa por la editora Zig-Zag, la distribuye la subsidiaria chilena de Visión Inc., cuya sede matriz también se encuentra en Nueva York ${ }^{19}$.

\footnotetext{
${ }^{18}$ Esta empresa no se contenta con administrar la revista Selecciones, introduce en el país otras publicaciones que pertenecen a una cadena de la cual Selecciones es sólo uno de los productos (véase a título de ilustración el Almanaque Mundial, Buen Hogar, Enciclopedia sobre Salud Femenina, etc.). Anotemos además que en el curso del año 1969, la Editorial América con sede administrativa en Miami y con su agencia distribuidora general en Panamá ha penetrado el Mercado Chileno. Citemos en particular la introducción de las nuevas fotonovelas quincenales: Susana y Candilejas distribuidas en toda América Latina. El grupo Ed. América es también propietario de los derechos de Vanidades Continental.

${ }^{19} \mathrm{El}$ mismo grupo Visión Inc., miembro de la sip distribuye a la vez una revista que se autodenomina de Información económica, editada en Nueva York y titulada Progreso, portavoz de los neocapitalistas latinoamericanos. El Director del grupo Visión Inc., es Alberto Lleras, antiguo presidente de Colombia cuyas posiciones malthusianas son ampliamente conocidas por el público latinoamericano (véase por ejemplo Visión, vol. $27, \mathrm{~N}^{\circ} 3$, mayo de 1964 y Progreso, enero-febrero de 1968). Para ser exhaustivo, sería necesario agregar a estas revistas dependientes aquellas menos importantes de tipo vulgarización científica.
} 
Armand Mattelarl / La dependencia de los medios de comunicación de masas en Chile

Un segundo grupo lo constituyen las revistas que pertenecen a la llamada industria del comic. La invasión de los comics strips remonta al año 1928, fecha en la cual los tres gigantes de la distribución de las tiras cómicas, el King Features Syndicates (KFs), el Chicago Tribune Daily News Syndicate y el United Features Syndicate, a los cuales vinieron a sumarse otros syndicates menos importantes, centralizaron la producción $y^{\prime}$ se encargaron de comercializarlos a nivel mundial. Resultado: en I 969 , los comics strips del King Features, por ejemplo, son traducidos en más de 30 idiomas, en más de 100 países y publicados en más de cinco mil diarios. Chile no escapó a la regla y los comics han penetrado en la esfera de las revistas y de los diarios. Ya hemos anotado en la sección anterior, la importancia de las revistas cómicas en la producción revisteril de las dos grandes editoriales chilenas (Lord Cochrane y Zig-Zag). En total alrededor de 350 mil ejemplares, repartidos sobre una decena de variedades, desde la tira cómica a stricto sensu hasta el "adventure strip". A esta producción nacional haría falta sumar los comics importados de México que, desde comienzos de 1969 , han literalmente invadido el mercado chileno.

\section{El comic strip en el diario}

Sólo en los diarios de izquierda (El Siglo y Ultima Hora) y en aquel de extrema derecha (El Diario Ilustrado), aunque para este último no fue siempre el caso, no tiene la tira cómica de origen norteamericano derecho de ciudadanía. Para los dos primeros diarios, huelga agregar que en cambio figuran tiras cómicas auténticamente nacionales, que representan ya sea un ensayo de interpretación irónica de la realidad sociopolítica (Inocentadas, de El Siglo); ya sea una expresión humorística de algunos rasgos de la vida cotidiana del pueblo (Benjamín de El Siglo y Lo Chamullo, un barrio como el suyo de la Ultima Hora). El Clarín es otro diario donde el comic norteamericano tiene escasa ingerencia: sólo dos páginas del suplemento dominical están dedicadas a tiras de vulgarización científica (en julio de 1969 se reproducian Nueva Era y Mark Trail ambas distribuidas por el Editor Press Service de Nueva

artisticas, etc. Citemos por ejemplo la Historia de la Música, Don Quijote, Naturalia, Decoralia, la $2^{a}$ guerra mundial, Belleza y encanto, etc., distribuidas por Publi Chile S. A. 
ESTUDIOS INTERNACIONALES lork). Aparece cada día una heroína humorística de sello nacional, que constituye la única tira publicada. En cambio en la prensa de los grupos económicos que, según vimos, tiene el número más elevado de lectores, suplementos dominicales enteros o parciales están dedicados a los comic strips de diversa índole. Estas publicaciones siguen por lo demás, aunque en menor proporción, en el curso de la semana. Ilustremos con algunos ejemplos.

\section{Diario El Mercurio:}

a) En el suplemento dominical de 4 páginas. En promedio çada una de estas historietas cómicas comporta 3 tiras de 3 . a 4 estampas $^{20}$. W. Disney: Ralón Mickey y Tío Remus, cuyos derechos reservados proceden de las Walt Disney productions y del King Features Syndicates (KFS). O. Soglow: El Reyecito (KFs); Chic Young: Pepila (KFs); Lyman Young y Tom Massey: Aventuras de Aguilucho (KFs); Bill Kavanagh y Vernon Green: Amenidades del Diario Vivir (Continuación de la serie Bringing up Father (KFS); Charles Flanders y Paul S. Newman: El Guardián Solitario (KFs).

b) En el curso de la semana, (cada una de las historietas cuenta con un promedio de una tira con 304 estampas), se publican: Dick Wingert: Pomponio (United Feature Syndicates); Bill Kavanagh y Vernon Green: Amenidades del diario vivir (KFs); Moco (Los Angeles Times); Getterman: Pelusa. A veces se publica también una historia de James Bond.

c) Haciendo la competencia se hallan tres tiras nacionales publicadas diariamente (de 3 a 4 estampas): El vagabundo, Don Perejil; el oficinista simplón, Artemio; el burgués, Don Memorario.

Hasta 1968 cada miércoles aparecía un suplemento infantil de historietas cómicas "Mampato". Fue reemplazado por una revista de idolos Topsi, que se analiza en el curso de esta obra. A título de ilustración damos los títulos de las historietas que figuraban en el suplemento semanal: Walt Disney: Pillín (KFs); Bob Montana: Archie (KFs); Stan Drake: El Diario de una vida (KFs); John Cullen Murphy: El Gran Ben Bolt (KFs); Dick Wingert: Pomponio (KFs); Frank Robbins: Juan el Intrépido (KFS).

${ }^{20} \mathrm{El}$ ejemplo escogido se refierc al mes dic julio de 1969. 
Armand Mallelart / La dependencia de los medios de comunicación de masas en Chile Gran parte de estas historietas fueron absorbidas por el diario del mismo grupo Las Ultimas Noticias que cada día de la semana, además de un suplemento semanal, publica las tiras siguientes: $\mathrm{H}$. Hanan: $F a-$ talicio, Editors Press Service; W. Disney: El Ratón Mickey (KFs); Dan Barry: Roldán el temerario (KFs); Briford Tune: Dotly, Editors Press Service; Simms Campbell: Chispas (KFs); Ken Bald: El Dr. Kildare (KFs); Alex Raymond: Rip Kirby (KFs); Roy Crane: As Solar (KFs); Mell Graff: El Agenle Secreto X-9 (KFs). El único antídoto chileno consiste en una historieta humorística: Asi es la vida y punto (uno o dos grabados).

A la dependencia de estos diarios haría falta agregar aquella del tercer diario que publica el grupo: La Segunda, donde el panorama no cambia: un promedio de i I historietas por ejemplar además de numerosos grabados de vulgarización cientifica $o$ de entretenimiento (adivinanzas, etc.).

El mismo fenómeno se vuelve a repetir en La Tercera de la Hora que en su suplemento del domingo llega a publicar: Lee Falk: Mandrake al Mago (KFs) y El Fantasma (KFs); Benitín y Eneas (S. de Beaumont); La Gata de Tobita (Editors Press Service); Brick Bradford (KFs); Kerry; Drake (Editors Press Service). A estos vendrían à sumarse tres historietas que aparecen en el cuerpo del diario: El Pato Donald, Quintín y el Doctor Morgan, distribuídos respectivamente por KFs y Editors Press Service. En contraposición, una sola historieta de corte nacional Pepe Antártico, (4 líneas dé2 ó 3 grabados) en el suplemento.

Por último citemos La Nación que publica cada día Tarzán (de Edgard Rice Burroughs), ukf; Juan Merino (de Sam Lefl y Mc Williams), UkF; Dick Tracy (de Chester Gould), The Chicago Tribune.

Un ejemplo de dependencia ideológica: el comic strip como estrategia de delución

Después de este acopio de datos morfológicos, nos parece interesante examinar, de manera más detallada, el modo de actuar propio à las tiras cómicas. Se trata de una ilustración que elegimos, entre otras, porque 
constituye uno de los casos más representativos de la colonización norteamericana de carácter masivo ${ }^{21}$.

Algunos autores pretenden que la invasión de los comic strips en las revistas y en la prensa cotidiana de los diversos países latinoamericanos, no es sino la prolongación de un fenómeno universal que hace que el haz de revistas brindadas a los lectores no sea fundamentalmente diferente en los diversos países del mundo. Por ejemplo, en Francia, los diarios de gran tiraje, tales como L'Aurore, Le Parisien Libéré, Paris Jour y France Soir, ofrecen cotidianamente a sus lectores un promedio de Io episodios previamente comprados a la King Features Syndicates, por intermedio de su filial francesa Opera Mundi..

Sin negar el valor de este argumento, es menester anotar primero, que sólo la prensa mercantil dominada por grupos económicos manipula este fenómeno universal llamado de los comic strips. Esta observación nos lleva a cuestionar el alcance exacto del término universal en la praxis. Numerosos analistas afirman que el proceso de identificación que se observa entre el público de diversos países - a menudo situados en antípodas culturales- y los héroes de ciertas tiras cómicas es un proceso que traduce el universalismo de los valores que su mensaje cobija. De esta forma, el héroe sería despegado de su soporte original y los valores que defiende pertenecerían a un fondo común convertido en patrimonio mundial.

Tomemos un ejemplo: la heroína del melodrama "El Diario de una Vida", por Stan Drake, uno de los más grandes éxitos mundiales de los comic strips (apareció en un suplemento de El Mercurio) sería de este modo, un modelo para la francesa, la norteamericana y la latinoamericana en pos de un ideal de mujer emancipada. La socióloga Evelyne Sullerot, por lo demás, ya ha destacado la influencia sorprendente de esta heroína sobre las mujeres de América del Sur "que descubren a través de ella que una mujer como ellas puede ejercer un oficio y asumir res-

${ }^{21}$ Para una visión general sobre los comics, consultar: J. .Marny, Le Mande étonnant des Bandes déssinées, Ed. le Centurion, Sciences humaines, Paris, 1968; Jules Gritti y colaboradores, Mass Media Editions Bloud et Gay, Paris, 1966 págs. $65-80$; Umberto Eco, Apocalípticos e inlegrados ante la cultura de masas, Editorial Lumen, Barcelona, I968; Oscar Masotta, "Reflexiones presemiológicas sobre la historieta: el esquematismo" en Lenguaje y comunicación social, op. cit., Buenos Aires, 1969 . 
Armand Mattelart / La dependencia de los medios de comunicación de masas en Chile ponsabilidades"22. Aún cuando estas últimas aserciones nos parecen sujetas a caución, el ejemplo de la influencia de esta heroína nos permite estudiar el verdadero alcance del universalismo del modelo. Hay que reconocer que el universalismo del modelo de emancipación, que encarna la heroína, está construido a partir de la extrapolación de un conjunto de valores reunidos en una muchacha norteamericana que vive, como dice el catálogo del King Features, "la vida de una familia con sus problemas, sus alegrías y sus esperanzas" y por ende se halla tributaria de una cultura específica. El ideal de emancipación que esta mujer representa no es un ideal de emancipación universal, sino la emancipación como la entiende el american way of life con sus deformaciones matriarcales y feministas. Sólo es universal la aspiración de la mujer a autodeterminarse, pero la forma de esta autodeterminación, que la revista propone a su lectora por intermedio de la heroína, pasa por la modalidad norteamericana.

A través de un ejemplo de este tipo, uno puede percibir la estrategia imperialistá en el modelo vehiculizado por un banal comic strip. Se ve, pues, que es el progreso y la penetración masiva de este modelo particular en el mundo lo que determina su carácter universal: adquiere este carácter a medida que va comercializándose e imponiéndose, por la vía comercio-publicitaria, en cada vez más países. Su expansión (el hecho que se le traduzca en más de treinta idiomas y que sea publicado en más de 600 diarios) hace olvidar su origen. De ahí, el modo difuso de su influencia lo hace alcanzar la categoría universal: el modelo como aspiración de todas las mujeres del mundo.

El hecho de que la mujer chilena o la mujer francesa, independientemente de una coyuntura cultural diferente, puedan identificarse con este modelo no se explica porque el mensaje es universal, sino porque ellas están influidas en grado similar por esta concepción particular que el imperialismo eleva al rango de ideal común. Ambas mujeres reflejan las aspiraciones de una sociedad alcanzada por el desafío americano. Nos apresuramos en decir que en el libro de Servan Schreiber el diagnóstico de esta forma de dependencia, cual es la ideológica, no se encuentra presente. Es una falla magistral puesto que, al no conside-

${ }^{252}$ E. Sullerot en J. Marny, Le Monde étonnanl des Bandes dessinées. Ed. Le Centurion, Op. cil., pág. 2.57 . 


\section{E S T U D I OS I N T E R N A C I O N A L E S}

rar el imperialismo en su totalidad ideológica, lo que propone en última instancia es un proceso de norteamericanización administrado por los propios franceses.

En realidad; el modo de acción de la mayoría de los comic strips puede ser enfocado desde el punto de vista de la imposición de una concepción peculiạr, que sirve para legitimar las estructuras de la sociedad -y sus ramificaciones externas - en que el modelo radica. Esta aserción, por lo demás, la vienen a respaldar pruebas explícitas: la movilización de los héroes en función de la coyuntura política. Flash Gordon, el héroe de ciencia ficción que, antes de i $94^{\circ}$, luchaba en el planeta de los Mongos, combate a los alemanes durante la śegunda guerra mundial. Superman; creado para compensar la idea del superhombre de la raza Aria, lucha a su vez en contra'de los éspías del Reich y Buz Sawyer, comandante de la Marinä norteamericana (de Roy Crane), después de haber peleado en el Pacífico contra los japoneses, defiende ahora los valores democráticos en las selvas del Vietnam. Por último, Juan el Intrépido, otro héroe al cual la cia confía misiones, enfrenta el peligro comunista a través de su variante china. Todos estos casos nos indican la extrema flexibilidad del héró quien, en caso de necesidad, se moviliza para defender el imperio norteamericano. Por cierto, se puède objetar, que se trata de héroes típicamente militares o paramilitares. Verémos, oportunamente, que támbién el personaje cómico, aparentemente inofensivo, puede adquirir una incidencia ideológica.

Es un tema ya ampliamente rastreado, a saber, que el modo de construîr el relato fácilita enormemente la incursión de la ideología implícita en el campo de las tiras cómicas; donde se encuentran héroes superhombres (Superman, Batman), héroes policiales (Dick Tracy, Rip Kirby); héroes de la magia y de lo fantástico (Mandrake el Mago y el Fantasma), héroes de ciencia ficción (Flash Gordon, Brick Bradford), héroes del Western y finalmente los héroes medievales" (el Príncipe Valiente). En efecto, el héroe de estas historietas tiene por función esencial la de restaurar el orden y luchar en contra de la injusticia y el despotismo. Encarna la lucha entre el bien y el mal $^{23}$. Pero, como no

\footnotetext{
${ }^{23}$ Ya Marx, alrededor de $185^{\circ}$, habia apuntado, en su análisis de la novela folletín, "Les mystéres de Paris" de Eugéne Sue, esta forma de organizar los personajes alrededor de la duali-
} 
Armand Mattelart / La dependencia de los medios de comunicación de masas en Chile existe un bien abstracto o un mal abstracto, los héroes luchan en la realidad por principios, o por estructuras, que encarnan este bien y estigmatizan los principios y las estructuras que vehiculizan el mal. La epopeya del héroe, en defensa de la libertad y en contra de la opresión, suele tornarse en la defensa de la democracia tal como la concibe Washington y el héroe toma por su cuenta la política intervencionista del "big stick". Citemos un caso preciso: "Flash Gordon, es lo que puede llamarse un héroe intachable, hermoso tipo humano de elevadas virtudes morales luchando solitariamente en contra de la tiranía. Pero también es un americano típico, demócrata, queriendo a toda costa hacer apreciar a los demás, hasta incluso imponerles, un modo de vida política del cual está convencido que es el mejor, sobre todo frente al opresor: de él podría decirse que es a la vez el Príncipe Valiente y Wilson ${ }^{, 24}$. Otros ejemplares: el hijo de un Lord inglés arrojado a una isla y recogido por una manada de simios, Tarzán, pertenece también a esta estirpe que, por su acción vigorozamente paternalista, hace reinar el orden inteligente del colonizador blanco en la jungla africana. Muchos de los héroes prestan también su ayuda al FBI. o a la cra., para el restablecimiento del orden puesto en peligro por los cómplices de $\mathrm{Al} \mathrm{Ca}$ pone o espías enigmáticos.

A la inversa, la estructura maniqueista de la repartición de personajes suele convertir a las "razas inferiores" en los malos que toman rasgos simiescos, tienen la piel amarilla $y$ aplastan su pueblo y sus víctimas bajo la férula del totalitarismo. No tan lejos de nosotros se encuentra el héroe James Bond cuyo carácter reaccionario y fascista ya subrayó Umberto Eco, dandos a sus observaciones un alcance teórico. "Fleming es reaccionario porque procede por esquemas. La construcción por esquemas, la bipartición maniqueista siempre es dogmática, intolerante. El demócrata es aquel que rechaza los esquemas y que reconoce los matices, las distinciones y justifica las contradicciones... Si

dad Bien/Mal, que en esta obra se confundía con aquella Ricos/Pobres. Véase en este sentido "Souscription de la forme. A propos d'une analyse des mystéres de Paris par Marx dans la Sainte Famille" par Marcelin Pleynet en Linguistique et Litterature, La Nouvelle Critique Paris, $\mathbb{N}^{\circ}$ especial, 1969, pp. 101-107.

${ }^{24}$ P. Couperie et E. Francois, "Flash Gordon" en Phénix, Paris, $2^{\circ}$ Trimestre, $1967, \mathrm{~N}^{\circ} 3$, pág. 6. 
E S T U D I O S I N T ER N A C I O N A L E S

Fleming es fascista, lo es porque pertenece al fascismo el ser incapaz de pasar de la mitología a la razón y tender a gobernar, valiéndose de mitos y de fetiches"

El"family strip" y la dilución de la protesta juvenil

La ideología subyacente al héroe opera de manera más sutil en el "family strip", que también se moviliza para absorber fenómenos que, si se desenvuelven sin ambages, pueden amenazar el establishment. Tomemos un ejemplo: Al lanzar en el mercado, en igi2, el personaje del marido dominado y su mujer, representativa del matriarcado norteamericano, George Mac Manus quiso tipificar en Bringing up father ("Amenidades del diario vivir") una familia norteamericana producto de la movilidad social rápida. El, inmigrante, antiguo albañil y ella, antigua lavandera, se enfrentan a la dificultad de adaptación con un estrato social al cual acaban de ingresar. Ahora bien, esta familia anodina en la cual muchas de las familias norteamericanas debieron reconocerse, ha servido últimamente para diluir ciertas formas de protesta juvenil, tal como el fenómeno "hippie". Para retomar una expresión empleada en una sección anterior, este comic strip ha sido utilizado para traducir lo insólito en una cosa conocida y conocible. La fuerza de persuasión del mensaje implícito. de una tira cómica sobre la situala situación de una familia común y corriente, es tanto más eficiente cuanto que su modo de operar es difuso y que el estilo jocoso es quizás, al nivel de la opinión pública, el instrumento más acertado para reducir las fuentes de subversión del orden social e integrarlas en los estereotipos de una cultura.

La tira cómica a que aludimos no es el único caso en el cual șe intenta diluir el fenómeno hippie. Al echar ưn vistazo sobre las diversas tiras cómicas que circulan en la actualidad, uno percibe de pronto que numerosas de ellas enfocan el problema de la rebelión juvenil bajo este ángulo. Es así como el "adventure strip" también saca su inspiración en el conflicto juvenil. Se trata, por ende, de una ofensiva general que confiere a la tira cómica la característica de ser la cristalizadora de problemas

${ }^{25}$ Umberto Eco: "James Bond: une combinatoire narrative" en Communications, París, Ig66, $N^{\circ} 8$, pág. $9^{2}$. 
Armand Mallelart / La dependencia de los medios de comunicación de masas en Chile sociales contemporáneos ${ }^{26}$. Ilustremos esta estrategia de dilución con dos ejemplos recientes:

i) Diálogo de la historieta: Amenidades del diario vivir: Los incomprendidos, publicada en el suplemento dominical de El Mercurio, 20/7/Ig6g. (3 actores: El, el marido; Ella, la esposa; un sobrino hippie, apodado familiarmente, Hipito, con las características formales del hippie: cabellos largos, pies desnudos en sandalias, collar típico, traje llamativo).

Ella: La pieza de Hipito está toda desordenada.

El: El no ticne tiempo para arreglar. ¡Está ocupado "reconstruyendo" la sociedad!

El: Hipito, tu pieza es un revoltijo... ¿Por qué no la ordenas?

Hipito: Ahora estoy "meditando", tío (Hipito está durmiendo siesta).

El: ¡Bueno, olvidate de meditar y empieza a trabajar!

Hipito: Ya lo haré, déjeme tomar aliento.

El: Hacer moverse a ese hippie es más dificil que hacer hablar a un mudito...

El: (un poco después) ¡Tal como pensę! ¡No ha hecho nada aún!

Hipilo: (lelefoneando a uno de sus amigos). Los viejos no nos comprenden; hay que comenzar a trabajar por la nueva generación.

El: ¡Y Ya verá ése! (y agarrando a Hipito) ¡A trabajar incomprendido!

Nadie podrá sustentar que esta estrategia de dilución aplicada al fenómeno hippie no es, sino más eficaz por lo menos, tan eficaz como un editorial de un diario liberal, tal como aquellos que analizamos más adelante en el cuerpo de la obra (cap. III, sec. 6). En esta tira cómica se encuentran, indistintamente, bajo su disfraz humorístico las grandes explicaciones - y a la vez las medicaciones - que da la ideología burguesa a la revolución ético-sexual que pretende realizar el movimiento hippie en los Estados Unidos. El par oposicional trabajador-ocioso es la clave de toda estrategia de reducción de este tipo de fenómeno. Para la burguesía el hippie es un joven ocioso que se las da de rebelde en contra de los "viejos" (lucha generacional) y que, al no querer trabajar, elabora un conjunto de racionalizaciones a posteriori para justificar su ociosidad. En este marco racionalizador entra, por ejemplo, la meditación. Es de interés contraponer esta visión de la burguesía con un texto

\footnotetext{
${ }^{26}$ Por cierto, la mayor parte de las tiras cómicas reproducidas en los diarios y las revistas no tienen este carácter de actualidad coyuntural; la mayoría actúa más bien bajo un ángulo estructural más indirecto.
} 
E S T U D I O S I N T E R N A C I O N A L E S

de Herbert Marcuse sobre, el significado que reviste el fenómeno hippie en los Estados Unidos: "Su rebelión está dirigida en contra de una moral puritana, en contra de una sociedad americana donde se lavan diez veces al día y que a la vez mata y quema en Vietnam con toda pureza. Entonces protestan metódicamente en contra de esta hipocresia llevando sus cabellos largos, sus barbas, no lavándose y negándose ir a la guerra. Para ellos la contradicción es deslumbradora',27

El mismo procedimiento de reducción bonachón se encuentra en la tira cómica Pomponio de Dick Wingert, cuyo personaje principal pertenece también al mundo hippie, (ver por ejem. El Mercurio, I I de junio de Ig69, pág. 2I). Citemos un último hecho de utilización del comic strip que, esta vez por ser aislado, no deja de ser anecdótico. La USAID (Agencia Internacional de Desarrollo de los Estados Unidos), ha decidido recientemente promover el héroe Pato Donald en personaje principal de una película, para propugnar el empleo de anticonceptivos en las políticas poblacionales de los países de América Latina. Nada extraño, puesto que el Pato Donald, soporte de una ideología implícita, no hace de esta manera sino operacionalizar esta ideología, explicitándola a través de un dominio particulàr de la acción del imperialismo. Es demostrar también, cuán seguro está el imperialismo de su infraestructura cultural para convencer a las masas de lo bueno de su sistema. Tomemos ahora otro ejemplo de operación de dilución a través de una historia de aventuras.

2) Diálogo de un adventure strip, tipo policial, titulado Kerry Drake, publicada en el Suplemento del Domingo 20 de julio Ig6g de La Tercera de la Hora, pág. 15. (Anotemos la extraordinaria coincidencia de las fechas de aparición con el family strip comentado anteriormente).

-El detective privado $\mathrm{K}$. Drake acaba de terminar su misión capturando una mujer traficante dè drogas que abastecía a un grupo de jóvenes. El detective y el padre de uno de estos jóvenes van a visitar al hijo, hospitalizado por ingestión excesiva de drogas.

El padre: es el señor Drake, un detective privado, Gerry. El ha logrado atrapar a la mujer que te vendia las drogas $y$ ahora está presa.

El hijo (Gerry) ¡No estoy interesado en conocer a tus amigos de sociedad, papá! No quie-

\footnotetext{
${ }^{27} \mathrm{H}$. Marcuse, citado en Agnés Guillou, "Marcuse: pour quoi faire?" La NEF, Paris, $\mathrm{N}^{\circ} 3^{6}$, enero-febrero 1969 , pág. 24 .
} 
Armand Mattelart / La dependencia de los medios de comunicación de masas en Chile ro pertenecer a la sociedad que afirmando ayudar a otros, ataca la honradez, el amor y la noviolencia como crímenes.

El detective: ¡Muchas ratas como las que envié a la cárcel están promoviendo el deshonor, la miseria y la violencia para hacerse de DINERo, vendiéndoles los "bombones" a Uds. los jóvenes! Y tú estás ayudándoles. No me importa lo que la droga te haga a ti, pero los médicos dicen que tus hijos pueden nacer DEForses y eso sí me importa. - ¡Dices que no apruebas el mundo del presente y te sales de él, pero no serán corregidos mediante sueÑos inducidos por drogas!

El hijo: ¡Solamente buscamos la respuesta de la pregunta "¿Quién soy?"

El detective: ${ }_{i}$ Te lo diré: Uds. son animales domésticos, quieren vivir șin trabajar, practicando el amor sin responsabilidades. ladrando hacia la luna mieritras tipos con valor arriesgan sus vidas para alcanzarla!

Si uno debe creer a ciertos censores morales del medio de comunicación de masas que estiman que lo que es reprensible en la tira cómica, las películas, etc., es su carga de violencia, de vulgaridad y de pornografia, esta tira que acabamos de presentar debiera ser un modelo de gran alcance moralizante. Ahora bien, es justamente por su aspecto moralista que el medio de comunicación de masas liberal es el más peligroso para la formación o la deformación de la conciencia de los individuos. La única solución que se le propone a este drogadicto es integrar la sociedad, adhiriendo por su trabajo a los valores de esta sociedad que, a pesar de todo, no se encuentra tan mal como lo pretenden profetas de mal agüero. Vemos aquí que la función moralizante que cumple el mensaje se realiza a través de un esquema maniqueista. Las alțernativas para el joven son claras y se resumen, en definitiva, en una elección que debe hacerse entre el mal centrado en el mundo de la droga y el bien, simbolizado por la sociedad existente con todos sus defectos. El binomio se caracteriza, a su vez, por calificaciones repartidas en formas dicotómicas:

Mal

Marginación por la droga (sueño)

Ocio

-Irresponsabilidad

Seguidismo

Delincuencia

Deshonor

Violencia.
Sociedad

Integración por rẹalidad

Trabajo

Esfuerzo

Valor 
E S T U D I O S I N T ER N A G I O N A L E S

En el campo estrecho de este dualismo, los aspectos negativos, que cataliza el ámbito del mal, vienen a reafianzar la legitimidad de la sociedad y la necesiảad del acto de integración de parte de cada individuo. Desde luego esta sociedad tiene defectos, pero como en todas las sociedades estos defectos no son sino anomalías sociales que se pueden corregir. Según el esquema maniqueista, las causas de la inquietud de este jo. ven drogadicto no pueden radicar en las instituciones sociales, ya que, el achacar a la sociedad la culpa implicaría reconocer que no son anomalías sociales que sufre la sociedad, pero sí fallas estructurales que atañen los principios que la legitiman. La causa principal del hábito de la droga debe, por lo tanto, hallarse en un registro que no pondrá en tela de juicio el statu quo. Será, esencialmente, primero el carácter modelable de la juventud que se deja embaucar por los traficantes en pos de beneficios; será luego, la aspiración a una vida ociosa (vivir sin trabajar, practicar el amoi sin responsabilidades, etc.). Nada extraño tiene el hecho que, al nivel de la medicación, el moralista no encuentre otra cosa que proponer al individuo su reintegración a la sociedad merced a su trabajo. El diagnóstico de las causas del mal, que se sitúan todas en el plano de la personalidad individual, sólo puede conducir al detective, convertido en siquiatra, a aconsejar este tratamiento para erradicar la inquietud juvenil. Existe un paralelismo sorprendente entre esta actitud y aquellas de numerosos gobiernos que, para aplacar la rebelión estudiantil, califican a los protestarios de ociosos y ios devuelven a sus estudios para que aprendan. Hay que reconocer la lógica del sistema. En la medida en que la causa del mal que afecta al individuo de un sector social se radica en su personalidad, el único remedio para suprimir este mal es un tratamiento de orden sicológico y no un cambio en las instituciones sociales. Tenemos aquí un caso típico de sicologismo que abordaremos en forma más profundizada en el tercer capitulo.

Mediante este ejemplo que, en principio, parecía insignificante, uno puede percatarse dónde están los puntos neurálgicos de la influencia invasora del medio de comunicación. La violencia y la pornografía no son los problemas más importantes. Sólo cobran importancia, desde un punto de vista eurístico, en la medida en que se encaran como productos de representaciones colectivas -estas últimas en relación íntima con el sistema de valores de la clase dominante- $y$, en la medida, en que su enjuiciamiento cuestiona los privilegios y las estructuras de poder monopoli- 
Armand Mattelart / La dependencia de los medios de comunicación de masas en Chile zadas por dicha clase. Toda denuncia de los efectos de los medios de comunicación de masas, como incitando a la violencia, vulgaridad y a la pornografía, que se aleje de este principio fundamental, corre el riesgo de hundirse en una tautología, puesto que se recurre al concepto burgués para condenar un subproducto necesario del orden burgués. La clase dominante, por lo demás, tiene amplio interés en que sea su concepto de la violencia $\mathrm{y}$ las bases de su actitud moralista las que sirvan de instrumentos para la denuncia: in foeto está el fracaso de este profetismo denunciador que no puede superar el verbalismo. De hecho significa entrar en la lógica implacable del sistema de la clase dominante ${ }^{28}$.

\section{LA DEPENDENCIA IDEOLOGICA}

Con el punto anterior, queda bien sentado el hecho de la presencia material de focos de dependencia en los medios de comunicación de masas. Sus agentes, sin previa modificación, importan los muy variados mensajes de la ideología del polo dominante externo. Sin embargo, cabe destacar cuanto antes que ya sobran los estudios que no superaron este umbral analítico. No menos importante es el punto de vista de la dependencia que experimenta la mayoria de los otros medios que suelen considerarse oficialmente chilenos y que se clasifican de buenas a primeras, entre los antídotos de los productos literarios, cinematográficos, etc., importados. Demos ejemplo: en comparación coh revistas tales como Claudia, Burda, Elle, muchas revistas, femeninas chilenas, como Paula y Eva, pueden jactarse de ser revistas autóctonas y de reflejar aspiraciones e inquietudes de la mujer chilena. Así, el comic strip donde figura el building de Chicago o el vendedor de Ice cream, puede parecer una realidad enajenante para quien la contrapone a la fotonovela criolla cuya acción se desarrolla en los alrededores de la estación Mapocho o del edificio Tajamar de Santiago.

Ahora bien, el carácter idiosincrático o la chilenización de la mayor parte de la prensa y de la radio no siempre es sinónimo de nacionalización. Aquí se abre paso el interrogante más fundamental, a saber, en qué medida la chilenización del medio no significa, en la realidad, una

${ }^{28}$ Remitirse tamibién al capítulo III, sec. $3^{a}$, donde demostraremos el aspecto tautológico de la denuncia burguesa sobre el carácter nocivo de los mensajes de los medios de comunicación de masas. 
E S T U D I O S I N T ER N A C I O N A L E S dependencia disfrazada donde la clase dominante administra la importación y la difusión de modelos de desarrollo social, arraigados en otra realidad. Desde esta perspectiva, si llegamos a demostrar la inserción de modelos alienados de desarrollo social en sentido lato, en los padrones de aspiraciones y valores que vehiculizan ciertas revistas o diarios chilenos, habremos probado, por el mismo hecho, la hegemonia de la potencia imperialista y podremos colocar los grupos chilenos entre los administradores del proyecto de dominación internacional. La publicación chilena no dejaría de ser, entonces, una nueva adaptación más o menos lograda del mensaje emitido por el polo dominante foráneo. Ya apuntamos que este interrogante no encontraría su respuesta definitiva sino al cabo de esta obra. Sin embargo, desde ahora, es indispensable fijar algunos puntos de reflexión que servirán de referencias pivotales a lo largo de los diversos capítulos del libro.

I. La mitología, que acuña la clase dominante, será una mitología dependiente en la medida en que el soporte de los mitos que se tratan de implantar, para constatar o explicar la realidad nacional a través del medio de comunicación de masas, se sitúa en otra realidad social.

2. Para captar las implicaciones de esta proposición hace falta retroceder y rastrear la génesis de la mitología burguesa. Según vimos, esta última puede describirse como la proyección ideal de una clase sobre la realidad. Funcionalmente, el mito burgués quita a la realidad su peso dialéctico, es decir, elimina de la sociedad, por él explicada, la lucha de clases y las raíces históricas de la desigualdad social. La operación principal que realiza la clase dominante al gestar el mito es, ante todo, imponer la imagen implicita de un cierto esquema de estratificación social. En el medio de comunicación de masa liberal, el problema mayor del soporte de la mitología dependiente estriba, por lo tanto, en la estratificación social que subtienden sus mensajes. Podremos hablar de dependencia sólo en la medida en que el esquema de estratificación social que el medio de comunicación conlleva, es un esquema vigente en otra realidad.

Al tener el mito por función presentar la imagen de una sociedad homogénea, armoniosa y sin problemas de conflictos de clase, reales 0 . potenciales, no puede subentender sino que la expresión modal de la sociedad nacional se encuentra en la clase media. En efecto, la imagen de armonía social que se afana en imponer sólo puede encontrarse en una sociedad 
Armand Mattelort / La dependencia de los medios de comunicación de masas en Chile integrada, es decir, una sociedad donde el estrato medio es el más numeroso y constituye el ejemplo del justo medio, del equilibrio.

Ahora bien, elevar al rango de tipo modal de una nación, la clase media, implicaria que en la realidad a la cual uno se refiere, la mayoría de los individuos tengan la posibilidad de integrar libremente este status. En otros términos, involucraría la existencia de una verdadera movilidad social ascendente para todos los individuos, independientemente de su origen social. La existencia de esta movilidad pues, permite la conformación de una sociedad construida a partir del modelo de estratificación social tricotómica, donde la clase con más peso sería la clase media. En la realidad chilena, el hecho de izar a la clase media como representativa de la nación significa eregir un $20 \%$ de la población al rango de modelo haciendo, además, abstracción del hecho que la clase media de un país de estratificación social rígida es cualitativamente distinta, debido a su situación de privilegio, de una clase media de un país con profusa movilidad.

3. Al promover en sus representaciones de la sociedad nacional una imagen de sociedad integrada formalmente, el medio de comunicación liberal adopta como parámetro una realidad de países capitalistas industrializados y, además, toma su modelo de aspiraciones hacia este tipo de sociedad por alcanzar como si ya fuera una realidad en su propio país.

4. Una vez efectuada la elección implícita de este tipo de sociedad, integrarán la mitología burguesa las características universales de este estrato medio - cuyos contornos quedan informes y por ende semejante al de cualquier país del mundo - es decir, el acceso total a los bienes de consumo. En otros términos el medio de comunicación liberal no hace otra cosa que formalizar, en un esquema artificial de estratificación, "realidades sociales ya deliberadamente simplificadas y reducidas a índices formales de consumo. Lo político, lo social, lo económico (estructuras de producción y de mercado), lo cultural, todos estos aspectos se volatilizan. Sólo queda lo cifrable al nivel de lo individual masificado, el balance estadístico de los bienes de consumo tomados como indicadores absolutos de la esencia social"29. En esa imagen, incluso la elite se reduce a ser portadora, no de valores ni de poder, sino de objetos $y$, por tanto, parece fácilmente acequible a las masas alcanzadas por la "revolución de las expectativas crecientes". Hasta las nociones jurídico-políticas de la ideología de la

${ }^{29} \mathrm{~J}$. Baudrillard "La morale des objets" en Comunications, París ${ }_{196 g_{r}} \mathrm{~N}^{\circ}{ }_{13}$, pág. 47 . 
E S T U D I O S I N T E R N A C I O N A L E S

clase dominante pasan por el tamiz del ideal de consumo. Es así como, para retomar un slogan propagandístico que circula en una radio capitalina, no se habla de Democracia para todos, pero de $T$. $Y$. para todos. De alguna manera, el acceso libre a los bienes de consumo, se convierte en el índice supremo de la existencia de una democracia en las sociedades de estratificación social rígida. De ahí a que el diario, la revista, propongan a los individuos marginales, como ideal de desarrollo social, el ideal de integración a la modernidad, encarnada en la sociedad de abundancia, a la que sólo hay un paso, y la mitología burguesa lo franquea rápidamente.

Al proponer el ideal de modernidad y al juzgar a los individuos no integrados en función de ese criterio, la prensa liberal desvirtúa los reales cuellos de botella sociales. Al negar implícitamente la necesidad de una transformación radical, el medio de comunicación de masas liberal confía, al proceso de evolución mecanicista, ciertos ajustes indispensables para lograr la modernización. Al instilar padrones de aspiraciones orientadas hacia la sociedad de consumo, hacia lo que algunos han llamado un consumidorismo artificial, el medio de comunicación de masas tiende a incorporar el individuo y toda la nación a la cadena de los que mantienen o remozan el statu quo nacional e internacional ${ }^{30}$.

5. Por supuesto, detrás de los mitos que uniformizan los diversos estratos sociales, están presentes todas las teorías de las cuales se vale la clase dominante para justificar y racionalizar su sistema de dominación. Será tarea de los diversos estudios, el hacer emerger de los textos analizados modelos inmersos o manifiestos de organización de las relaciones sociales, de cultura, etc. Desde este punto de vista, puede considerarse, por ejemplo, los modelos dependientes de organización política como modelos en desajuste con el esquema de estratificación social vigente.

\footnotetext{
${ }^{30}$ Veamos por ej. para precisar esta óptica consumidorista las actas del ABC World Vision, uno de los trusts de T.V. más importantes de EE.Uu, encargados de la propaganda comercial en los paises del Tercer Mundo. "Las estaciones pertenecientes a la ABC World Vision alcanzan ya en 1963 a más de 15 millones de hogares. La capacidad de gastar de esta audiencia orientadora sobrepasa los us $\${ }_{13} 6$ millones de ingreso disponible. Son ellos los primeros en encariñarse con una marca y marcar el camino para otras", en Panorama Económico Latinoamericano, La Habana, $1969, N^{\circ} 312$, pág. 9. Sobre la influencia que ejerce el medio de comunic. de masas sobre el modelo de consumo, remitirse al informe de la cepal, El Cambio Social y la Política de Desarrollo Social en América Latina, Lima, Perú, $13^{\circ}$ período de sesiones, 14 al 23 de abril de ig6g.
} 